\title{
Bottlenecks in the transferability of antibiotic resistance from natural ecosystems to human bacterial pathogens
}

\author{
José L. Martínez* \\ Departamento de Biotecnología Microbiana, Centro Nacional de Biotecnología-Consejo Superior de Investigaciones Cientificas, Madrid, Spain
}

Edited by:

Stefania Stefani, University of

Catania, Italy

\section{Reviewed by:}

Julian Davies, University of British

Columbia, Canada

Teresa M. Coque, Hospital

Universitario Ramón y Cajal, Spain

*Correspondence:

José L. Martínez, Departamento de

Biotecnología Microbiana, Centro

Nacional de Biotecnología-Consejo

Superior de Investigaciones

Cientificas, Darwin 3, Cantoblanco,

28049 Madrid, Spain

e-mail:jImtnez@cnb.csic.es
It is generally accepted that resistance genes acquired by human pathogens through horizontal gene transfer originated in environmental, non-pathogenic bacteria. As a consequence, there is increasing concern on the roles that natural, non-clinical ecosystems, may play in the evolution of resistance. Recent studies have shown that the variability of determinants that can provide antibiotic resistance on their expression in a heterologous host is much larger than what is actually found in human pathogens, which implies the existence of bottlenecks modulating the transfer, spread, and stability of antibiotic resistance genes. In this review, the role that different factors such as founder effects, ecological connectivity, fitness costs, or second-order selection may have on the establishment of a specific resistance determinant in a population of bacterial pathogens is analyzed.

Keywords: horizontal gene transfer, antibiotic resistance, founder effect, fitness costs, genetic exchange community, second-order selection

\section{INTRODUCTION}

Bacterial pathogens can develop antibiotic resistance either by mutations, or by the acquisition of antibiotic resistance genes from other microorganisms through horizontal gene transfer (HGT). Since bacterial pathogens were (presumably) susceptible to antibiotics at the time of the development of these compounds, it is reasonable to think that resistance genes have been acquired from non-pathogenic microorganisms. Indeed, the analysis of Escherichia coli plasmids from bacterial strains isolated before and after the use of antibiotics for therapy demonstrated that the plasmid families were similar, but incorporated resistance genes after the antibiotic era (Datta and Hughes, 1983).

Since the resistance genes did not originate in bacterial pathogens, the sources for these genes would be environmental microorganisms (Martinez et al., 2009a; Davies and Davies, 2010). Indeed, the fact that most antibiotics currently used in clinics originated in environmental microorganisms (Waksman and Woodruff, 1940) led to the proposal that the origin of resistance genes are the antibiotic-producing organisms, where resistance genes may play an auto-protective role (Benveniste and Davies, 1973; Davies, 1997). Recent work indicates that indeed antibioticproducing environmental microorganisms harbor a large number of resistance genes that could be potentially transferred to human pathogens (D'Costa et al., 2006). Nevertheless, the presence of resistance genes in the environment is not confined to antibiotic producers (Aminov, 2009). For instance, the quinolone resistance gene qnrA originated in the water-borne bacteria Shewanella algae, which is not known to produce an antibiotic (Poirel et al., 2005). Given that quinolones are synthetic drugs, the existence of these determinants indicate the antibiotic resistance genes can have disparate functions in their original hosts, in such a way that the universe of potential resistance genes that can be incorporated into mobile genetic elements is even larger than predicted from the analysis of antibiotic producers. Support for this statement is the finding of genes that contribute to intrinsic resistance in different bacterial species (Fajardo et al., 2008; Tamae et al., 2008; Girgis et al., 2009; Alvarez-Ortega et al., 2010; Liu et al., 2010) and functional metagenomic analyses indicating that the wide dissemination of a large number of resistance genes (D'Costa et al., 2006; Sommer et al., 2009) in all analyzed ecosystems (including the human gut) whether or not contaminated by human activities.

It would be expected that this diversity of resistance genes in microorganisms, that can confer an antibiotic resistant phenotype on their transfer to a new host might be mirrored by a large variability of resistance genes, acquired by HGT, in human pathogens. However, the number of different resistance determinants found among human bacterial pathogens is low in comparison to those present in the different metagenomes. This indicates that the transfer of a resistance gene from its original host to a human pathogen might be constrained by different bottlenecks, as discussed in this review.

\section{THE TWO FACES OF ANTIBIOTIC RESISTANCE DETERMINANTS: HOUSEKEEPING GENES AND HUMAN-DRIVEN CONTAMINANTS}

The existence of resistance genes in natural ecosystems, even those without any record of pollution by antibiotics was reported more than four decades ago (Gardner et al., 1969). However, detailed studies on this topic are more recent. In the last years an increasing number of studies of the presence of resistance genes in nonclinical ecosystems have been published. Several are based on non-culture methods for detecting resistance. Briefly, two different methodologies are applied; one is the search for any potential gene that confers resistance on expression in a heterologous host by using functional genomic techniques (D'Costa et al., 2006, 2011; Sommer et al., 2009). The other is the search for resistance 
genes already present in human pathogens, usually by PCR, in metagenomic DNA (Koike et al., 2007). Whereas, in the first analysis the purpose is to characterize any gene that can cause resistance if transferred and hence study the potential natural resistome of the studied ecosystem, the second type of study analyses contamination by resistance genes already acquired by human pathogen.

These studies thus provide different information. Functional metagenomics serves to define novel mechanisms of resistance (potentiality, see Martinez et al., 2007), but predicting whether such mechanisms will be transferred to human pathogens is not obvious (see below). Indeed, the fact that the origin of the antibiotic resistance genes currently present in human pathogens is known in only a few cases indicates that defining the environmental resistome is a needed but not sufficient condition for predicting the emergence of resistance. It is important to note however that the finding of novel mechanisms of resistance can be a valuable tool for the design of antibiotic modifications before resistance arises (Wright, 2007; Martinez et al., 2011).

The analysis of the presence in different ecosystems (contaminated and pristine) of genes that have been already acquired by human pathogens would provide information on the stability of these elements, the reservoirs and the factors that enrich their presence in nature. These studies can be used to evaluate the risks for human health from pollution of natural ecosystems by antibiotic resistance determinants, together with antibiotics that serve as selectors of resistance themselves (Martinez, 2008, 2009). This knowledge might serve for the identification of intervention strategies to reduce the impact of anthropogenic activities on the enrichment of resistance elements, already present in mobile genetic elements (MGEs), in natural (non-clinical) ecosystems (Baquero et al., 2008). The relevance that farming and transport of food-borne animals or pets (Guardabassi et al., 2004; Aarestrup, 2005; Moreno et al., 2008), as well as the transport of goods (Ruiz et al., 2000), or human migration (Kumarasamy et al., 2010) may have for the dissemination or resistance is well known. For these processes, procedures for tracking the presence and dissemination of resistance genes might be implemented. More difficult will be the implementation of such studies for analyzing the role of wild animals in the spread of resistance (Gilliver et al., 1999; Livermore et al., 2001; Allen et al., 2010). Important in this respect is the finding of resistance in migratory birds that can disseminate both antibiotic resistance determinants and infective resistant bacteria all over the world (Middleton and Ambrose, 2005; Steele et al., 2005; Simoes et al., 2010).

Between these types of studies are functional analyses on the resistance mobilome, those resistance genes that are already present on mobile elements, irrespective of whether or not they have been acquired by human pathogens. The transfer of a potential resistance gene from the chromosome of an environmental bacterium to a human pathogen requires it to be mobilizable after its capture by a translocative element and its integration in an MGE. This means that once the resistance element has been incorporated in a mobile element, the possibility of its acquisition by a human pathogen can be high, especially if this element is present in the human bacterial population. Unfortunately, studies on the environmental resistance mobilome are difficult and still rare (Szczepanowski et al., 2008, 2009; Moura et al., 2010; Parsley et al., 2010).

\section{ECOLOGICAL CONNECTIVITY}

The first requirement for the transfer of a resistance gene is that both the donor and the receptor share the same habitat. In the case of pathogenic bacteria, the pathogens need not co-exist with the donor, because a chain of microorganisms may link the donor and the recipient. However, since acquiring resistance genes might confer a fitness cost (see below), the establishment of a successful gene-transfer chain is possible only with positive selection for the resistance determinant. In other words, unless resistance is selected (mainly by antibiotics), it is unlikely that MGEs containing resistance genes will be fixed in the populations of environmental microorganisms en route to human pathogens. Since the natural concentrations of antibiotics in non-clinical ecosystems are much lower than at hospitals (Davies, 2006), only in the case of pollution by antibiotics (aquaculture, waste disposal from cities, farms, or industries) a positive selection for MGEs containing resistance genes can be envisaged. Following this reasoning, it has been proposed that the possibility of a given resistance gene being transferred to a human pathogen will largely depend on whether the habitat where the donor micro-organism is present close to human-linked ecosystems (Baquero et al., 2009). For instance, it would be rare for resistance genes found in deep soil allocations (Brown and Balkwill, 2009) or at a glacial ice core (Miteva et al., 2004) would be transferred to human pathogens. In contrast, it has been suggested that ecosystems such as waste-water treatment plants or farms, where human pathogens and environmental bacteria co-exist in the presence of contaminating antibiotic residues, might be hot-spots for the acquisition of resistance genes by bacterial pathogens (Baquero et al., 2008; Aminov, 2011).

Ecological connectivity is not restricted to the spatial distribution of microorganisms. For those microorganisms sharing the same ecosystem, some of them are more prone to exchange genetic material than others. The organisms that can share genes, have been named as genetic exchange communities (Jain et al., 2003). As stated in (Skippington and Ragan, 2011), "gene exchange communities can vary widely in spatial extent, taxonomic diversity, density of internal connectivity, and involvement of vector types." These communities usually share some plasmid (or transposon) types and do not possess strong restriction/modification systems that would impede the interchange of DNA. As a consequence, the entrance of a resistance gene, located in a proficient MGE into a well established gene exchange community might allow its spread among different organisms and consequently fixation in populations of bacterial pathogens. This spread will be modulated by specific fitness costs that preclude the stability of the gene in some bacterial species.

\section{FOUNDER EFFECT}

By founder effect, we refer to the situation in which the first gene to arrive is the one to win (Baquero et al., 2009). When there are several resistance determinants with a similar substrate profile, usually one prevails once transferred to human bacterial pathogens. As we will discuss later, this situation can be the consequence of differential fitness costs, nevertheless, a certain 
degree of serendipity might be the basis of the successful transfer, spread and fixation of a given resistance determinant. One example of this situation is the TEM-1 beta-lactamase, which, followed by SHV-1 and OXA enzymes, has been the predominant plasmid-encoded beta-lactamase in Enterobacteriaceae for many years (Simpson et al., 1980; Medeiros, 1997). The TEM-1 betalactamase was acquired soon after the introduction of the first generation of beta-lactams for therapy, and plasmids coding this beta-lactamase spread rapidly among bacterial pathogens. The study of several different ecosystems has shown that there exist a large number of beta-lactamases nearly everywhere, which can confer resistance to the same antibiotics as TEM-1. Why then, has TEM-1 prevailed in these pathogen populations? Antibiotic resistance genes are acquired and maintained because of the strong selective pressure of antibiotics. Once bacteria have acquired a determinant that allow them to resist antibiotics, there is not a selection pressure for replacement of the determinant already present in bacterial populations. This situation can change if the selective pressure is altered, for example when new antibiotics are launched into clinical use (Livermore, 2009; Salverda et al., 2010). Indeed, the introduction of beta-lactamase inhibitors and novel beta-lactams for which TEM-1 presented low activity generated two different processes: (i) evolution of the TEM-enzyme that most likely occurred in clinical settings when bacterial pathogens were exposed to the novel selective pressure (ii) acquisition of novel beta-lactamase coding genes by human pathogens with novel substrate profiles.

\section{FITNESS COSTS}

It is generally assumed that the acquisition of an antibiotic resistance determinant confers a fitness cost (Andersson and Levin, 1999), meaning that in the absence of selection, resistant bacteria will be outcompeted by the susceptible ones. In the case of genes acquired by HGT, these costs might be the consequence of the metabolic load imposed by the replication, transcription, and translation of the novel genetic elements. If this was the unique cause of fitness costs, the disadvantage of carrying one or another resistance gene will be similar and the fitness cost would not constitute a relevant bottleneck in selecting one resistance determinant over another. However, different studies have shown that, at least on occasion, the introduction of a given resistance gene does not impose a non-specific metabolic burden but leads to specific changes in bacterial physiology. This may be the case for AmpC beta-lactamase genes, which are infrequently found on Salmonella plasmids unless the plasmid also harbors the repressor of their expression (Verdet et al., 2000) or elements that compensate the biological costs associated to AmpC expression (Hossain et al., 2004). It has been found that AmpC alters the physiology of Salmonella, decreasing its virulence and hence a differential fitness cost that decreases the probability of dissemination of specific gene among Salmonella strains (Morosini et al., 2000). This example indicates that the fitness costs can be gene-specific and do not necessarily derive from a general metabolic burden. In this context, those resistance determinants conferring high fitness costs are unlikely to be fixed in bacterial populations because they would be outcompeted by other resistance determinants which lower fitness costs (Martinez et al., 2011).
This reasoning must be however modified by the chances of acquiring compensatory mutations (Andersson and Hughes, 2011; Martinez et al., 2011). If a resistance determinant confers high fitness costs, but compensatory mutations are easily selected, the probability of being maintained in bacterial pathogens is high. In such cases, the location of the mutations is a relevant issue. If the compensatory mutations occur in the chromosome, not in the MGE, the acquisition of the resistance gene by a new host implies a new fitness cost, and as a consequence the spread of the resistance determinant will be compromised. However, it the mutation occurs in the MGE, the chances for spread will be enhanced.

\section{SECOND-ORDER SELECTION AND MAINTENANCE OF RESISTANCE GENES IN THE ABSENCE OF SELECTION}

If the acquisition of resistance confers fitness costs it is logical to suppose that resistant organisms will be outcompeted by their susceptible, fitter counterparts in the absence of selection. However, some resistant strains present no-cost (Rozen et al., 2007; Balsalobre and De La Campa, 2008) and even some resistance determinants can be beneficial under certain conditions (Alonso et al., 2004; Maughan et al., 2004; Luo et al., 2005; Perkins and Nicholson, 2008; Michon et al., 2011). Finally, some fitness costs can be compensated by mutations that do not impede to keep resistance (Bjorkman et al., 1998; Maisnier-Patin et al., 2002; Paulander et al., 2007; Lind et al., 2010; Shcherbakov et al., 2010). This indicates that reversing resistance once established can be a difficult task (Andersson and Hughes, 2010).

Maintenance of resistance genes in habitats without a strong antibiotic pressure is favored as well by second-order selection processes. Antibiotic resistance genes on MGEs are usually in association to other resistance determinants. This means that the selection for one antibiotic will select for the whole array of resistance genes present in this specific MGE. Furthermore, MGEs besides resistance genes may carry other elements such as heavymetal resistance determinants (Baker-Austin et al., 2006), or genes coding for production of siderophores, toxins, or bacteriocins (De Lorenzo and Martinez, 1988; Clewell, 1990; Herrero et al., 2008); these can confer an ecological advantage in some ecosystems and thus co-select resistance in the absence of antibiotics. Cross-selection might also be a relevant second-order process that allows maintenance of resistance in the absence of selection. Certain resistance determinants, such as multidrug (MDR) efflux pumps confer resistance to different compounds (antibiotics, biocides, or heavy metals; Martinez et al., 2009b). This means that selection with the biocide or the heavy metal might result in crossresistance to the antibiotic (Hernandez et al., 1998; Sanchez et al., 2005).

A final mechanism for the maintenance of resistance is based on the inherent systems for plasmid stability. Plasmids frequently encode toxin/antitoxin systems, which provoke death of bacteria that lose the plasmid (Hayes, 2003; Hayes and Van Melderen, 2011). If one such plasmid incorporates an antibiotic resistance determinant, the probabilities for its maintenance will be high.

Taking these considerations into account, resistance genes might evade elimination (Andersson and Hughes, 2011) in the absence of antibiotics; indeed, resistance determinants present in human pathogens have been found on identical MGEs, in 
antibiotic-pristine habitats (Pallecchi et al., 2008) such as wild animals (Gilliver et al., 1999; Livermore et al., 2001) and primitive human populations without any known exposure to antibiotics (Grenet et al., 2004; Bartoloni et al., 2009). These observations indicate that anthropogenic activity has enriched for a small number of resistance genes in natural ecosystems and that this type of pollution will be difficult to eradicate (Salyers and AmabileCuevas, 1997; Martinez, 2009). Supporting this notion, analyses of soils sampled in The Netherlands from 1940 to 2008, reveal that the abundance of different antibiotic resistance genes increased during this period. This, in spite of the fact that restrictions on non-therapeutic use of antibiotics in agriculture and in waste management procedures have been strongly enforced (Knapp et al., 2010).

\section{CONCLUSION}

Research on antibiotic resistance has been mainly focused on bacterial pathogens isolated from infections or in clinical settings. However, the fact that HGT-acquired genes originated in natural, non-clinically relevant microorganisms and that the first step in the transfer of resistance likely occurs in natural ecosystems emphasizes the need to analyze resistance in non-clinical ecosystems. Furthermore, the constant release of antibiotic resistance determinants already present in MGEs located in human

\section{REFERENCES}

Aarestrup, F. M. (2005). Veterinary drug usage and antimicrobial resistance in bacteria of animal origin. Basic Clin. Pharmacol. Toxicol. 96, 271-281.

Allen, H. K., Donato, J., Wang, H. H., Cloud-Hansen, K. A., Davies, J., and Handelsman, J. (2010). Call of the wild: antibiotic resistance genes in natural environments. Nat. Rev. Microbiol. 8, 251-259.

Alonso, A., Morales, G., Escalante, R., Campanario, E., Sastre, L., and Martinez, J. L. (2004). Overexpression of the multidrug efflux pump SmeDEF impairs Stenotrophomonas maltophilia physiology. J. Antimicrob. Chemother. 53, 432-434.

Alvarez-Ortega, C., Wiegand, I., Olivares, J., Hancock, R. E., and Martinez, J. L. (2010). Genetic determinants involved in the susceptibility of Pseudomonas aeruginosa to beta-lactam antibiotics. Antimicrob. Agents Chemother. 54, 4159-4167.

Aminov, R. I. (2009). The role of antibiotics and antibiotic resistance in nature. Environ. Microbiol. 11, 2970-2988.

Aminov, R. I. (2011). Horizontal gene exchange in environmental microbiota. Front. Microbiol. 2:158. doi:10.3389/fmicb.2011.00158

Andersson, D. I., and Hughes, D. (2010). Antibiotic resistance and its cost: is it possible to reverse resistance? Nat. Rev. Microbiol. 8, 260-271.
Andersson, D. I., and Hughes, D. (2011). bacterial populations. FEMS Microbiol. Rev. 35, 901-911.

Andersson, D. I., and Levin, B. R. (1999). The biological cost of antibiotic resistance. Curr. Opin. Microbiol. 2, 489-493.

Baker-Austin, C., Wright, M. S., Stepanauskas, R., and Mcarthur, J. V. (2006). Co-selection of antibiotic and metal resistance. Trends Microbiol. 14, 176-182.

Balsalobre, L., and De La Campa, A. G. (2008). Fitness of Streptococcus pneumoniae fluoroquinoloneresistant strains with topoisomerase IV recombinant genes. Antimicrob. Agents Chemother. 52, 822-830.

Baquero, F., Alvarez-Ortega, C., and Martinez, J. L. (2009). Ecology and evolution of antibiotic resistance. Environ. Microbiol. Rep. 1, 469-476.

Baquero, F., Martinez, J. L., and Canton, R. (2008). Antibiotics and antibiotic resistance in water environments. Curr. Opin. Biotechnol. 19, 260-265.

Bartoloni, A., Pallecchi, L., Rodriguez, H., Fernandez, C., Mantella, A., Bartalesi, F., Strohmeyer, M., Kristiansson, C., Gotuzzo, E., Paradisi, F., and Rossolini, G. M. (2009). Antibiotic resistance in a very remote Amazonas community. Int. J. Antimicrob. Agents 33, 125-129.

Benveniste, R., and Davies, J. (1973). Aminoglycoside antibiotic-inactiPersistence of antibiotic resistance in

pathogens, and in some circumstances associated with selective concentrations of antibiotics, may disrupt natural microbiota, which then serve as reservoirs for resistance genes. Non-culture based methods have demonstrated their value for the analysis of resistance in natural ecosystems. Among them, functional metagenomics provides the means to identify novel mechanisms of resistance independently of whether they will be acquired by bacterial pathogens. On the other hand, PCR analyses for specific genes serve to define reservoirs and to study elements like pollution in the dissemination and maintenance of resistance. Functional metagenomic studies indicate that very few among the resistance genes present in nature have been transferred to human pathogens. Whereas the founder effect can provide stochasticity to these acquisitions, other factors such as fitness costs, ecological connectivity, which includes the formation of gene exchange communities, are relevant bottlenecks that serve to modulate the acquisition of resistance genes by animal or human pathogens.

\section{ACKNOWLEDGMENTS}

The author's laboratory is supported by grants BIO2008-00090 from the Spanish Ministry of Science and Innovation and KBBE-227258 (BIOHYPO), HEALTH-F3-2010-241476 (PAR), and HEALTH-F3-2011-282004 (EVOTAR) from the European Union. Thanks are given to the referees for useful suggestions.

vating enzymes in actinomycetes similar to those present in clinical isolates of antibiotic-resistant bacteria. Proc. Natl. Acad. Sci. U.S.A. 70, 2276-2280.

Bjorkman, J., Hughes, D., and Andersson, D. I. (1998). Virulence of antibiotic-resistant Salmonella typhimurium. Proc. Natl. Acad. Sci. U.S.A. 95, 3949-3953.

Brown, M. G., and Balkwill, D. L. (2009). Antibiotic resistance in bacteria isolated from the deep terrestrial subsurface. Microb. Ecol. 57, 484-493.

Clewell, D. B. (1990). Movable genetic elements and antibiotic resistance in enterococci. Eur. J. Clin. Microbiol. Infect. Dis. 9, 90-102.

Datta, N., and Hughes, V. M. (1983). Plasmids of the same Inc groups in Enterobacteria before and after the medical use of antibiotics. Nature 306, 616-617.

Davies, J. (2006). Are antibiotics naturally antibiotics? J. Ind. Microbiol. Biotechnol. 33, 496-499.

Davies, J., and Davies, D. (2010). Origins and evolution of antibiotic resistance. Microbiol. Mol. Biol. Rev. 74, 417-433.

Davies, J. E. (1997). Origins, acquisition and dissemination of antibiotic resistance determinants. Ciba Found. Symp. 207, 15-27.

D’Costa, V. M., King, C. E., Kalan, L., Morar, M., Sung, W. W., Schwarz,
C., Froese, D., Zazula, G., Calmels, F., Debruyne, R., Golding, G. B., Poinar, H. N., and Wright, G. D. (2011). Antibiotic resistance is ancient. Nature 477, 457-461.

D’Costa, V. M., Mcgrann, K. M., Hughes, D. W., and Wright, G. D. (2006). Sampling the antibiotic resistome. Science 311, 374-377.

De Lorenzo, V., and Martinez, J. L. (1988). Aerobactin production as a virulence factor: a reevaluation. Eur. J. Clin. Microbiol. Infect. Dis. 7, 621-629.

Fajardo, A., Martinez-Martin, N., Mercadillo, M., Galan, J. C., Ghysels, B., Matthijs, S., Cornelis, P., Wiehlmann, L., Tummler, B., Baquero, F., and Martinez, J. L. (2008). The neglected intrinsic resistome of bacterial pathogens. PLoS ONE 3, e1619. doi:10.1371/journal.pone.0001619

Gardner, P., Smith, D. H., Beer, H., and Moellering, R. C. Jr. (1969). Recovery of resistance ( $R$ ) factors from a drug-free community. Lancet 2, 774-776.

Gilliver, M. A., Bennett, M., Begon, M., Hazel, S. M., and Hart, C. A. (1999). Antibiotic resistance found in wild rodents. Nature 401, 233-234.

Girgis, H. S., Hottes, A. K., and Tavazoie, S. (2009). Genetic architecture of intrinsic antibiotic susceptibility. PLoS ONE 4, e5629. doi:10.1371/journal.pone.0005629 
Grenet, K., Guillemot, D., Jarlier, V., Moreau, B., Dubourdieu, S., Ruimy, R., Armand-Lefevre, L., Bau, P., and Andremont, A. (2004). Antibacterial resistance, Wayampis Amerindians, French Guyana. Emerging Infect. Dis. $10,1150-1153$.

Guardabassi, L., Schwarz, S., and Lloyd, D. H. (2004). Pet animals as reservoirs of antimicrobial-resistant bacteria. J. Antimicrob. Chemother. 54, 321-332.

Hayes, F. (2003). Toxins-antitoxins: plasmid maintenance, programmed cell death, and cell cycle arrest. Science 301, 1496-1499.

Hayes, F., and Van Melderen, L. (2011). Toxins-antitoxins: diversity, evolution and function. Crit. Rev. Biochem. Mol. Biol. 46, 386-408.

Hernandez, A., Mellado, R. P., and Martinez, J. L. (1998). Metal accumulation and vanadium-induced multidrug resistance by environmental isolates of Escherichia hermannii and Enterobacter cloacae. Appl. Environ. Microbiol. 64, 4317-4320.

Herrero, A., Mendoza, M. C., Rodicio, R., and Rodicio, M. R. (2008). Characterization of pUOStVR2, a virulence-resistance plasmid evolved from the pSLT virulence plasmid of Salmonella enterica serovar Typhimurium. Antimicrob. Agents Chemother. 52, 4514-4517.

Hossain, A., Reisbig, M. D., and Hanson, N. D. (2004). Plasmid-encoded functions compensate for the biological cost of AmpC overexpression in a clinical isolate of Salmonella typhimurium. J. Antimicrob. Chemother. 53, 964-970.

Jain, R., Rivera, M. C., Moore, J. E., and Lake, J. A. (2003). Horizontal gene transfer accelerates genome innovation and evolution. Mol. Biol. Evol. 20, 1598-1602.

Knapp, C. W., Dolfing, J., Ehlert, P. A., and Graham, D. W. (2010). Evidence of increasing antibiotic resistance gene abundances in archived soils since 1940. Environ. Sci. Technol. 44, 580-587.

Koike, S., Krapac, I. G., Oliver, H. D., Yannarell, A. C., Chee-Sanford, J. C., Aminov, R. I., and Mackie, R. I. (2007). Monitoring and source tracking of tetracycline resistance genes in lagoons and groundwater adjacent to swine production facilities over a 3-year period. Appl. Environ. Microbiol. 73, 4813-4823.

Kumarasamy, K. K., Toleman, M. A., Walsh, T. R., Bagaria, J., Butt, F., Balakrishnan, R., Chaudhary, U., Doumith, M., Giske, C. G., Irfan, S., Krishnan, P., Kumar, A. V., Maharjan, S., Mushtaq, S., Noorie, T., Paterson,
D. L., Pearson, A., Perry, C., Pike, R., Rao, B., Ray, U., Sarma, J. B., Sharma, M., Sheridan, E., Thirunarayan, M. A., Turton, J., Upadhyay, S., Warner, M., Welfare, W., Livermore, D. M., and Woodford, N. (2010). Emergence of a new antibiotic resistance mechanism in India, Pakistan, and the UK: a molecular, biological, and epidemiological study. Lancet. Infect. Dis. 10, 597-602.

Lind, P. A., Tobin, C., Berg, O. G., Kurland, C. G., and Andersson, D. I. (2010). Compensatory gene amplification restores fitness after interspecies gene replacements. Mol. Microbiol. 75, 1078-1089.

Liu, A., Tran, L., Becket, E., Lee, K., Chinn, L., Park, E., Tran, K., and Miller, J. H. (2010). Antibiotic sensitivity profiles determined with an Escherichia coli gene knockout collection: generating an antibiotic bar code. Antimicrob. Agents Chemother. 54, 1393-1403.

Livermore, D. M. (2009). Betalactamases- the threat renews. Curr. Protein Pept. Sci. 10, 397-400.

Livermore, D. M., Warner, M., Hall, L. M., Enne, V. I., Projan, S. J., Dunman, P. M., Wooster, S. L., and Harrison, G. (2001). Antibiotic resistance in bacteria from magpies (Pica pica) and rabbits (Oryctolagus cuniculus) from west Wales. Environ. Microbiol. 3, 658-661.

Luo, N., Pereira, S., Sahin, O., Lin, J., Huang, S., Michel, L., and Zhang, Q. (2005). Enhanced in vivo fitness of fluoroquinolone-resistant Campylobacter jejuni in the absence of antibiotic selection pressure. Proc. Natl. Acad. Sci. U.S.A. 102, 541-546.

Maisnier-Patin, S., Berg, O. G., Liljas, L., and Andersson, D. I. (2002). Compensatory adaptation to the deleterious effect of antibiotic resistance in Salmonella typhimurium. Mol. Microbiol. 46, 355-366.

Martinez, J. L. (2008). Antibiotics and antibiotic resistance genes in natural environments. Science 321, 365-367.

Martinez, J. L. (2009). Environmental pollution by antibiotics and by antibiotic resistance determinants. Environ. Pollut. 157, 2893-2902.

Martinez, J. L., Baquero, F., and Andersson, D. I. (2007). Predicting antibiotic resistance. Nat. Rev. Microbiol. 5, 958-965.

Martinez, J. L., Baquero, F., and Andersson, D. I. (2011). Beyond serial passages: new methods for predicting the emergence of resistance to novel antibiotics. Curr. Opin. Pharmacol. 11, 439-445.

Martinez, J. L., Fajardo, A., Garmendia, L., Hernandez, A., Linares, J. F.,
Martinez-Solano, L., and Sanchez, M. B. (2009a). A global view of antibiotic resistance. FEMS Microbiol. Rev. 33, 44-65.

Martinez, J. L., Sanchez, M. B., Martinez-Solano, L., Hernandez, A., Garmendia, L., Fajardo, A., and Alvarez-Ortega, C. (2009b). Functional role of bacterial multidrug efflux pumps in microbial natural ecosystems. FEMS Microbiol. Rev. 33, 430-449.

Maughan, H., Galeano, B., and Nicholson, W. L. (2004). Novel rpoB mutations conferring rifampin resistance on Bacillus subtilis: global effects on growth, competence, sporulation, and germination. J. Bacteriol. 186, 2481-2486.

Medeiros, A. A. (1997). Evolution and dissemination of beta-lactamases accelerated by generations of betalactam antibiotics. Clin. Infect. Dis. 24(Suppl. 1), S19-S45.

Michon, A., Allou, N., Chau, F. Podglajen, I., Fantin, B., and Cambau, E. (2011). Plasmidic qnrA3 enhances Escherichia coli fitness in absence of antibiotic exposure. PLoS ONE 6, e24552. doi:10.1371/journal.pone.0024552

Middleton, J. H., and Ambrose, A. (2005). Enumeration and antibiotic resistance patterns of fecal indicator organisms isolated from migratory Canada geese (Branta canadensis). J. Wildl. Dis. 41, 334-341.

Miteva, V. I., Sheridan, P. P., and Brenchley, J. E. (2004). Phylogenetic and physiological diversity of microorganisms isolated from a deep greenland glacier ice core. Appl. Environ. Microbiol. 70, 202-213.

Moreno, A., Bello, H., Guggiana, D., Dominguez, M., and Gonzalez, G. (2008). Extended-spectrum betalactamases belonging to CTX-M group produced by Escherichia coli strains isolated from companion animals treated with enrofloxacin. Vet. Microbiol. 129, 203-208.

Morosini, M. I., Ayala, J. A., Baquero, F., Martinez, J. L., and Blazquez, J. (2000). Biological cost of AmpC production for Salmonella enterica serotype Typhimurium. Antimicrob. Agents Chemother. 44, 3137-3143.

Moura, A., Henriques, I., Smalla, K., and Correia, A. (2010). Wastewater bacterial communities bring together broad-host range plasmids, integrons and a wide diversity of uncharacterized gene cassettes. Res. Microbiol. 161, 58-66.

Pallecchi, L., Bartoloni, A., Paradisi, F. and Rossolini, G. M. (2008). Antibiotic resistance in the absence of antimicrobial use: mechanisms and implications. Expert Rev. Anti. Infect. Ther. 6, 725-732.

Parsley, L. C., Consuegra, E. J., Kakirde, K. S., Land, A. M., Harper, W. F. Jr., and Liles, M. R. (2010). Identification of diverse antimicrobial resistance determinants carried on bacterial, plasmid, or viral metagenomes from an activated sludge microbial assemblage. Appl. Environ. Microbiol. 76, 3753-3757.

Paulander, W., Maisnier-Patin, S., and Andersson, D. I. (2007). Multiple mechanisms to ameliorate the fitness burden of mupirocin resistance in Salmonella typhimurium. Mol. Microbiol. 64, 1038-1048.

Perkins, A. E., and Nicholson, W. L. (2008). Uncovering new metabolic capabilities of Bacillus subtilis using phenotype profiling of rifampinresistant rpoB mutants. J. Bacteriol. 190, 807-814.

Poirel, L., Rodriguez-Martinez, J. M., Mammeri, H., Liard, A., and Nordmann, P. (2005). Origin of plasmid-mediated quinolone resistance determinant QnrA. Antimicrob. Agents Chemother. 49, 3523-3525.

Rozen, D. E., Mcgee, L., Levin, B. R. and Klugman, K. P. (2007). Fitness costs of fluoroquinolone resistance in Streptococcus pneumoniae. Antimicrob. Agents Chemother. 51, 412-416.

Ruiz, G. M., Rawlings, T. K., Dobbs, F. C., Drake, L. A., Mullady, T., Huq, A., and Colwell, R. R. (2000). Global spread of microorganisms by ships. Nature 408, 49-50.

Salverda, M. L., De Visser, J. A., and Barlow, M. (2010). Natural evolution of TEM-1 beta-lactamase: experimental reconstruction and clinical relevance. FEMS Microbiol. Rev. 34, 1015-1036.

Salyers, A. A., and Amabile-Cuevas, C. F. (1997). Why are antibiotic resistance genes so resistant to elimination? Antimicrob. Agents Chemother. 41, 2321-2325.

Sanchez, P., Moreno, E., and Martinez, J. L. (2005). The biocide triclosan selects Stenotrophomonas maltophilia mutants that overproduce the SmeDEF multidrug efflux pump. Antimicrob. Agents Chemother. 49, 781-782.

Shcherbakov, D., Akbergenov, R., Matt, T., Sander, P., Andersson, D. I., and Bottger, E. C. (2010). Directed mutagenesis of Mycobacterium smegmatis 16S rRNA to reconstruct the in-vivo evolution of aminoglycoside resistance in Mycobacterium tuberculosis. Mol. Microbiol. 77, 830-840. 
Simoes, R. R., Poirel, L., Da Costa, P. M., and Nordmann, P. (2010). Seagulls and beaches as reservoirs for multidrug-resistant Escherichia coli. Emerging Infect. Dis. 16, 110-112.

Simpson, I. N., Harper, P. B., and O'Callaghan, C. H. (1980). Principal beta-lactamases responsible for resistance to beta-lactam antibiotics in urinary tract infections. Antimicrob. Agents Chemother. 17, 929-936.

Skippington, E., and Ragan, M. A. (2011). Lateral genetic transfer and the construction of genetic exchange communities. FEMS Microbiol. Rev. $35,707-735$.

Sommer, M. O., Dantas, G., and Church, G. M. (2009). Functional characterization of the antibiotic resistance reservoir in the human microflora. Science 325, 1128-1131.

Steele, C. M., Brown, R. N., and Botzler, R. G. (2005). Prevalences of zoonotic bacteria among seabirds in rehabilitation centers along the
Pacific Coast of California and Washington, USA. J. Wildl. Dis. 41, 735-744.

Szczepanowski, R., Bekel, T., Goesmann, A., Krause, L., Kromeke, H., Kaiser, O., Eichler, W., Puhler, A., and Schluter, A. (2008). Insight into the plasmid metagenome of wastewater treatment plant bacteria showing reduced susceptibility to antimicrobial drugs analysed by the 454-pyrosequencing technology. J. Biotechnol. 136, 54-64.

Szczepanowski, R., Linke, B., Krahn, I., Gartemann, K. H., Gutzkow, T., Eichler, W., Puhler, A., and Schluter, A. (2009). Detection of 140 clinically relevant antibiotic-resistance genes in the plasmid metagenome of wastewater treatment plant bacteria showing reduced susceptibility to selected antibiotics. Microbiology 155, 2306-2319.

Tamae, C., Liu, A., Kim, K., Sitz, D., Hong, J., Becket, E., Bui, A. Solaimani, P., Tran, K. P., Yang, H., and Miller, J. H. (2008). Determination of antibiotic hypersensitivity among 4,000 single-gene-knockout mutants of Escherichia coli. J. Bacteriol. 190, 5981-5988.

Verdet, C., Arlet, G., Barnaud, G., Lagrange, P. H., and Philippon, A. (2000). A novel integron in Salmonella enterica serovar Enteritidis, carrying the BLA(DHA-1) gene and its regulator gene ampR, originated from Morganella morganii. Antimicrob. Agents Chemother. 44, 222-225.

Waksman, S. A., and Woodruff, $\mathrm{H}$ B. (1940). The soil as a source of microorganisms antagonistic to disease-producing bacteria. J. Bacteriol. 40, 581-600.

Wright, G. D. (2007). The antibiotic resistome: the nexus of chemical and genetic diversity. Nat. Rev. Microbiol. 5, 175-186.

Conflict of Interest Statement: The author declares that the research was conducted in the absence of any commercial or financial relationships that could be construed as a potential conflict of interest.

Received: 13 September 2011; paper pending published: 06 October 2011; accepted: 12 December 2011; published online: 03 January 2012.

Citation: Martinez JL (2012) Bottlenecks in the transferability of antibiotic resistance from natural ecosystems to human bacterial pathogens. Front. Microbio. 2:265. doi: 10.3389/fmicb.2011.00265

This article was submitted to Frontiers in Antimicrobials, Resistance and Chemotherapy, a specialty of Frontiers in Microbiology.

Copyright () 2012 Martinez. This is an open-access article distributed under the terms of the Creative Commons Attribution Non Commercial License, which permits non-commercial use, distribution, and reproduction in other forums, provided the original authors and source are credited. 